P.G.ESO.561 - DOI: 10.22288/S0004-28032016000100561

\title{
ESTUDO DE PREVALÊNCIA E DAS CARACTERÍSTICAS HISTOLÓGICAS, CLÍNICAS E DEMOGRÁFICAS EM PACIENTES DIAGNOSTICADOS COM ESOFAGITE EOSINOFÍLICA NO HOSPITAL UNIVERSITÁRIO CLEMENTINO FRAGA FILHO
}

\author{
Fernando Marques Moreira de Castro / UFRJ; Guilherme Coelho / UFRJ; Luiz João Abrahao Júnior / UFRJ.
}

RESUMO - Contexto - A esofagite eosinofílica (EE) é uma doença inflamatória crônica do esôfago imunologicamente/alergicamente mediada caracterizada por sintomas de disfunção esofagiana e infiltrado eosinofílico proeminente na mucosa esofágica. Seus critérios diagnósticos são: sintomas de disfunção esofágica; infiltrado eosinofílico no exame histopatológico ( $\geq 15$ eosinófilos/cga) isolada do esôfago e que persistem após prova com inibidor de bomba protônica; exclusão de causas secundárias; e boa resposta terapêutica. Objetivo - Avaliar prevalência de EE nas endoscopias digestivas altas realizadas no Serviço de 01/01/2010 a 06/06/2016 e de sua confirmação histopatológica. Serão caracterizados os dados demográficos e a queixa que motivou a realização do exame. Métodos - Estudo retrospectivo de consulta à base de dados do SME de Gastroenterologia, aos dados computadorizados e aos prontuários dos pacientes. Foram avaliados: 1. O número de diagnósticos de suspeição de EE; 2. o número de pacientes que obtiveram a confirmação do diagnóstico histopatológico; 3. as características demográficas da população; 4.as queixas que motivaram a realização da EDA. Os dados foram digitados em programa Excel e posteriormente analisados. Resultados - No período estudado, 20 pacientes receberam o diagnóstico de suspeição de EE. Destes, apenas 9 tiveram o diagnóstico confirmado no exame histopatológico. Seis pacientes eram do sexo masculino e três do sexo feminino. A média de idade foi de 24 anos, variando de 12 a 66 anos. Oito apresentavam achados característicos à endoscopia (cinco com estenose, três com pontilhado brancacento, três com estrias longitudinais e um com traqueização) e em um o exame foi normal. Quatro necessitaram de dilatações endoscópicas para tratamento de estenoses. As sintomatologias predominantes foram de disfagia (7 pacientes) e impactação alimentar (6 pacientes). A pHmetria foi normal em 4 dos 5 pacientes estudados. A esofagomanometria foi alterada em 3 dos 5 avaliados (sem padrão predominante). Os pacientes responderam apenas parcialmente ao corticoide tópico. Conclusão - Apesar do relatado aumento de incidência na literatura, o diagnóstico de EE ainda é pouco frequente em nosso hospital. Neste grupo estudado a prevalência de estenose foi elevada o que pode refletir atraso no diagnóstico destes pacientes.

Contato: Fernando Marques Moreira. Hospital Universitário Clementino Fraga Filho(UFRJ). E-mail: fernandommcastro@gmail.com 